\title{
The Toxicity of Digestive Gland of Trumpet Shells Inhabiting the Coast of Shizuoka Prefecture
}

\author{
(Received July 8, 1985)
}

\author{
Hiroko Narita*1, Kaichiro Watanabe*1, Keisuke BabA*2, Hirohisa OHgami*2, \\ Toshio K. AI*2, Yasumasa Igarashi*2, Masato NARA*2, Tamao NoGUCHI ${ }^{* 3}$ \\ and Kanehisa HaSHIMOTO*3 \\ (*1Shizuoka Prefectural Institute of Public Health and Environmental Science: \\ Kita-ando 4-27-2, Shizuoka, Japan: *2Shizuoka Prefectural Fisheries Experi- \\ ment Station: Kogawa-shioiri 3690, Yaizu, Shizuoka, Japan; ${ }^{* 3}$ Laboratory \\ of Marine Biochemistry, Faculty of Agriculture, University of Tokyo: \\ Bunkyo, Tokyo, Japan)
}

A total of 691 specimens of a trumpet shell Charonia sauliae were collected from several locations in Shizuoka Prefecture, and assayed for toxicity of the digestive gland by the official method for tetrodotoxin determination.

1) The frequency of toxic specimens ranged from $30 \%$ at Ito to $93 \%$ at Shimizu, the average frequency being $66 \%$.

2) The average toxicity of all the specimens assayed was $151 \mathrm{MU} / \mathrm{g}$ digestive gland. The toxicity score was clearly higher at Shimizu $(226 \mathrm{MU} / \mathrm{g})$ or Numazu $(277 \mathrm{MU} / \mathrm{g})$ than at other places.

3) The highest toxicity scores recorded at Shimizu and Numazu were 1,950 and 2,580 $\mathrm{MU} / \mathrm{g}$ digestive gland, respectively. At other places, however, fairly toxic specimens (400-500 $\mathrm{MU} / \mathrm{g}$ digestive gland) were found sporadically.

4) The toxicity of trumpet shells in the Shimizu area has tended to decrease in recent years.

5) At Numazu, the toxicity of trumpet shells was higher in spring and summer than in other seasons. Shimizu specimens did not show such a seasonal variation.

Key words: trumpet shell; digestive gland; tetrodotoxin; gastropod mollusk

\section{Introduction}

In December 1979, a food poisoning incident occurred in Shizuoka Prefecture. A man, aged 41 , cooked and ate the digestive gland of a trumpet shell Charonia sauliae which had been caught off the Miho coast in Shimizu') $\mathrm{He}$ rapidly became seriously paralyzed, and was consequently hospitalized and treated for 13 days until he recovered completely. The causative agent was identified as tetrodotoxin (TTX $)^{1)}$. It was found that most of the trumpet shells collected off the Miho coast and adjacent waters of Shimizu were more or less toxic.

A similar poisoning incident took place in Wakayama Prefecture in 1982, and TTX was again confirmed to be the causative substance ${ }^{2)}$.
Subsequent surveys disclosed that the digestive glands of this carnivorous gastropod mollusk were of ten highly to moderately toxic, depending on the sampling location in several other prefectures: $\mathrm{Aichi}^{3)}, \mathrm{Mie}^{*)}$, Miyazaki ${ }^{4)}$ and $\mathrm{Ka}$ goshima $^{5)}$. In the course of those surveys, large regional variations of toxicity were noticed.

These circumstances led us to screen extensively the toxicity of trumpet shells inhabiting coastal areas in Shizuoka Prefecture, and the present study was undertaken.

* Noguchi, T., Maruyama, J., Jeon, J. K., Noda, H., Hashimoto, K.: Abstract of the Autumn Meeting of the Japanese Society of Scientific Fisheries (Oct. 1983, Kyoto), p. 189. 


\section{Experimental}

\section{Materials}

A total of 691 specimens of the trumpet shell C. sauliae were collected off the coasts of Omaezaki-cho, Shimizu, Numazu, Nishi-izu-cho, Minami-izu-cho and Ito in 1979-1984 (Fig. 1).

Immediately after collection of the specimens, the digestive glands were excised and assayed for toxicity as described below. Otherwise, the specimens were kept frozen at $-20^{\circ} \mathrm{C}$. They were partially thawed when required, then their digestive glands were removed, and used for mouse bioassay.

\section{Assay method for toxicity}

The digestive glands were individually assayed for toxicity by the official method of TTX determination using mice ${ }^{8)}$.

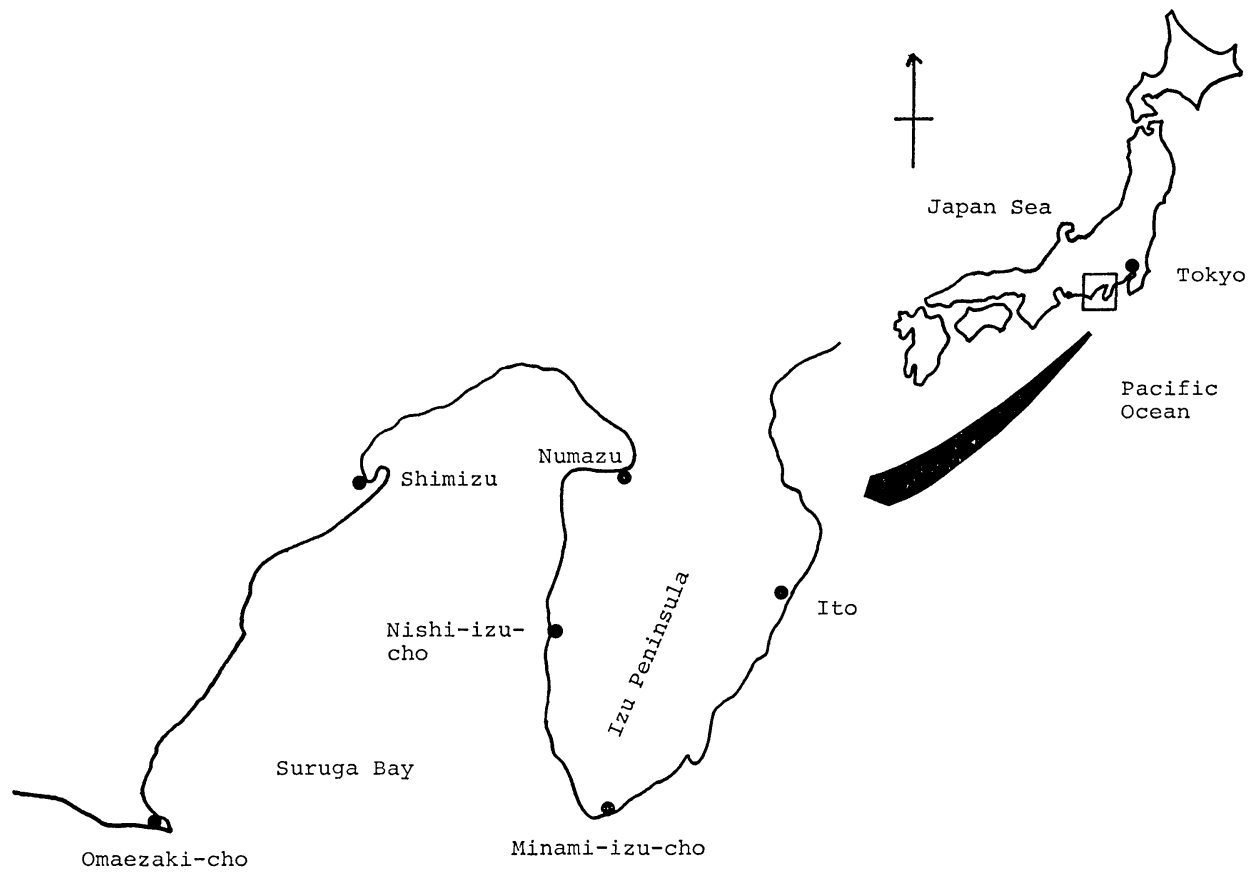

Fig. 1. Map showing the six sampling locations for trumpet shells in Shizuoka Prefecture

Table 1. Summary of the Toxicity of Trumpet Shell Specimens collected in Shizuoka Prefecture

\begin{tabular}{lcccc}
\hline \hline Place and year of collection & Frequency of toxic & $\begin{array}{c}\text { Average toxicity } \\
\text { specimens }\end{array}$ & $\begin{array}{c}\text { Highest toxicity } \\
\text { gland)*2 }\end{array}$ & $\begin{array}{c}\text { tive } \\
\text { (MU/g digestive } \\
\text { gland) }\end{array}$ \\
\hline Omaezaki-cho & 1981 & $33 \%(19 / 57) * 3$ & 2 & 17 \\
Shimizu*4 & $1979-1984$ & $93 \%(113 / 122)$ & 226 & 1,950 \\
Numazu & $1981-1984$ & $85 \%(227 / 268)$ & 277 & 2,580 \\
Nishi-izu-cho & $1981-1984$ & $39 \%(58 / 150)$ & 11 & 503 \\
Minami-izu-cho & 1980,1982 & $53 \%(18 / 34)$ & 3 & 22 \\
Ito & $1982-1984$ & $30 \%(18 / 60)$ & 8 & 422 \\
\hline \multicolumn{1}{c}{ Total } & & $66 \%(453 / 691)$ & 151 & \\
\hline
\end{tabular}

*1 "Toxic" is defined here as $2 \mathrm{MU} / \mathrm{g}$ digestive gland.

*2 Calculated on the assumption that the toxicity of "nontoxic" specimens was $0 \mathrm{MU} / \mathrm{g}$ digestive gland.

*3 No. of toxic specimens/Total No. of specimens assayed.

*4 Inclusive of our previous data ${ }^{1)}$. 


\section{Results and Discussion}

The results obtained are summarized in Table 1. Out of the 691 specimens assayed, $453(66 \%)$ were found to be toxic. The frequency of toxic specimens differed according to the sampling site, ranging from $30 \%$ at Ito to $93 \%$ at Shimizu.

The average toxicity of all the specimens was calculated to be $151 \mathrm{MU} / \mathrm{g}$ digestive gland. The average toxicity levels of the samples collected in Shimizu and Numazu, both situated in the northern part of Suruga Bay, were found to be $226 \mathrm{MU} / \mathrm{g}$ and $277 \mathrm{MU} / \mathrm{g}$, respectively, while those of samples from other locations were 2-11 MU/g.

Compared to the samples collected from Omae zaki-cho, Nishi-izu-cho, Minami-izu-cho and Ito, the shells from Shimizu and Numazu was found to be highly toxic (Table 1). Since the minimum lethal dose of TTX in the human is estimated to be $10,000 \mathrm{MU}^{7)}, 4-5 \mathrm{~g}$ of the digestive glands from

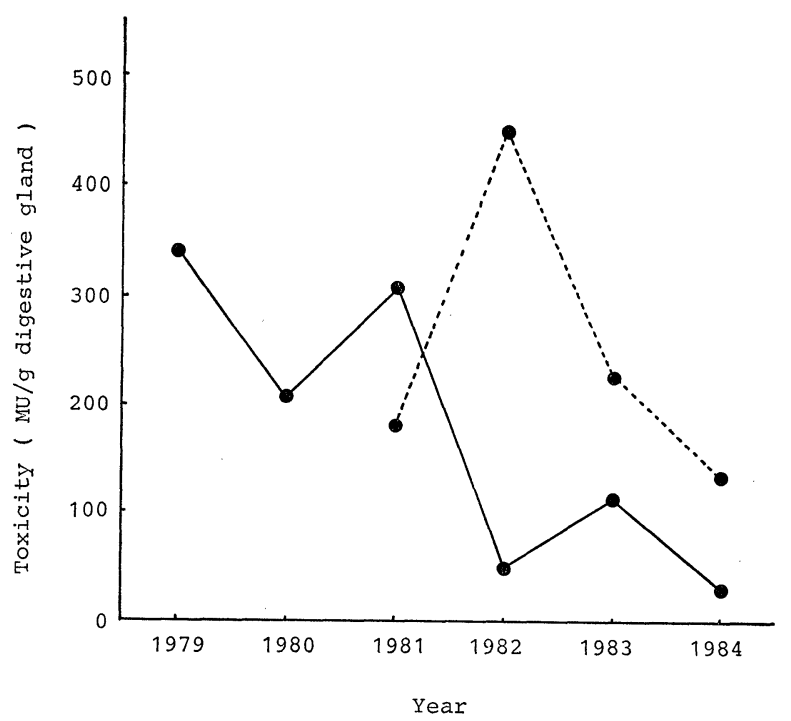

Fig. 2. Changes in the yearly average toxicity of trumpet shells at Shimizu (-) and Numazu

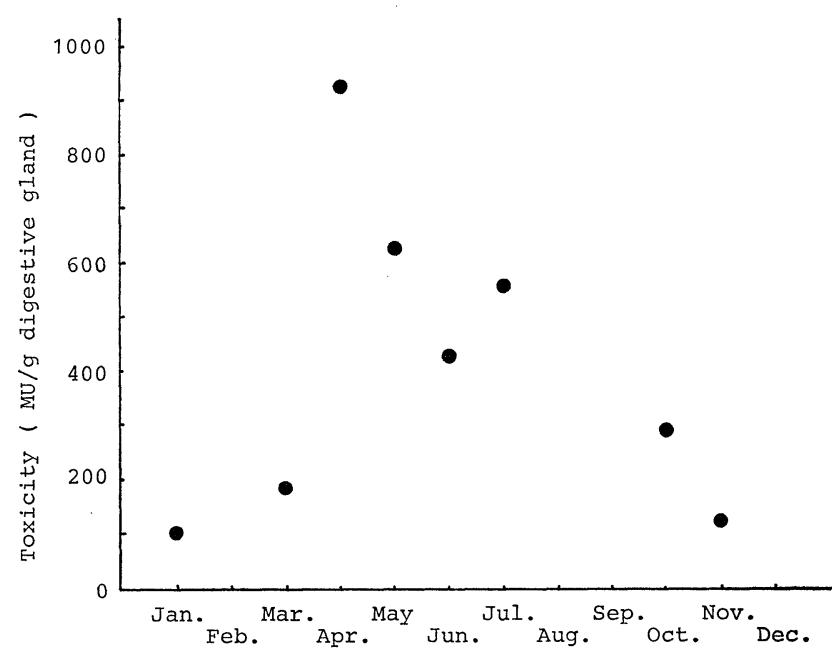

Fig. 3. Seasonal changes in the average toxicity of trumpet shells at Numazu 


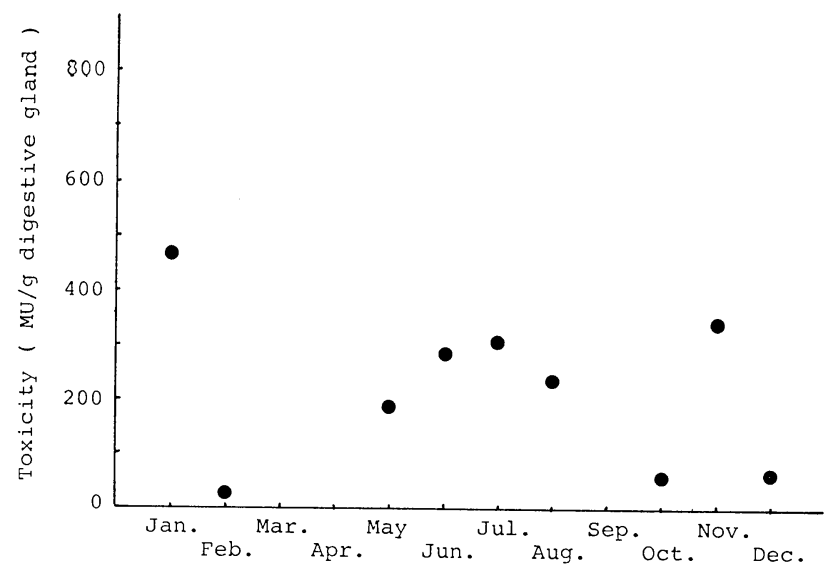

Fig. 4. Seasonal changes in the average toxicity of trumpet shells at Shimizu

Shimizu and Numazu may be sufficient to kill a man when ingested.

It was noteworthy that highly toxic specimens were found, though sporadically, in Nishi-izucho (e.g., $503 \mathrm{MU} / \mathrm{g}$ ) and Ito (e.g., $422 \mathrm{MU} / \mathrm{g}$ ), places where the average toxicity levels were very much lower (11 and $8 \mathrm{MU} / \mathrm{g}$ respectively).

Changes in the yearly average toxicity of trumpet shells are shown in Fig. 2. Shimizu specimens exhibited a general decrease in toxicity through the years covered, 1979-1984. On the other hand, the toxicity of Numazu specimens was highest in 1982, and has been decreasing in subsequent years.

Changes in monthly average toxicity of trumpet shells are shown in Figs. 3 and 4. The toxicity of Numazu specimens (Fig. 3) tended to increase in spring and early summer. However, Shimizu specimens did not clearly show such a seasonal change (Fig. 4).

Toxicity surveys of trumpet shells have so far been carried out in $\mathrm{Aichi}^{3)}$, Mie*, Wakayama ${ }^{2)}$, Miyazaki $^{4)}$, and Kagoshima ${ }^{5)}$ prefectures. In Shizuoka Prefecture, the frequency of toxic specimens was $66 \%$, with an average toxicity of $151 \mathrm{MU} / \mathrm{g}$ and highest score of $2,580 \mathrm{MU} / \mathrm{g}$ digestive gland, as described above. Comparing those values with those in other prefectures (Table 2), the digestive gland of trumpet shells seems to show rather high toxicity in Shizuoka Prefecture. Trumpet shells, however, show fairly wide variations in toxicity, depending upon the locality, season and year of collection. It

\footnotetext{
* See footnote on p. 15
}

Table 2. Comparison of the Toxicity of Trumpet Shells in Shizuoka Prefecture, with Those in Other Prefectures so far Reported

\begin{tabular}{lccr}
\hline \hline Prefecture & $\begin{array}{c}\text { Frequency of } \\
\text { toxic } \\
\text { specimens*1 }\end{array}$ & $\begin{array}{c}\text { Average } \\
\text { toxicity*2 }\end{array}$ & $\begin{array}{c}\text { Highest } \\
\text { toxicity*2 }\end{array}$ \\
\hline Shizuoka & $66 \%$ & 151 & 2,580 \\
Aichi & 84 & 27 & 479 \\
Mie & 66 & 85 & 460 \\
Wakayama & 68 & 45 & 480 \\
Miyazaki & 19 & 4 & 106 \\
Kagoshima & 43 & 81 & 1,670 \\
\hline
\end{tabular}

*1 Refer to the footnote in Table 1 .

*2 $\mathrm{MU} / \mathrm{g}$ digestive gland

is important to keep this in mind, along with the exclusive presence of TTX in the digestive gland $^{1)}$, in considering the edibility of this shell.

As demonstrated previously, trumpet shells are toxified by ingestion of a toxic starfish Astropecten polyacanthus, at least in the Shimizu area $^{8), 8)}$. Partial involvement of another toxic starfish, $A$. scoparious, was recently suggested ${ }^{10)}$. Since both starfishes are densely distributed along the coast of Numazu, they may well be responsible for the toxicity of trumpet shells there.

In this connection, the regional, yearly and seasonal variations in toxicity mentioned before could be related to the abundance of toxic starfishes, which is in turn controlled by various environmental and ecological factors.

The origin of TTX accumulated in toxic starfishes remains to be elucidated. 


\section{Acknowledgements}

The present research was supported in part by a research fund from the Ministry of Agriculture, Forestry and Fisheries. The authors are indebted to Director Dr. Y. Harada, Shizuoka Prefectural Fisheries Experiment Station, and Director Dr. T. Goto, Shizuoka Prefectural Institute of Public Health and Environmental Science, for continuous encouragement during the course of this research.

\section{References}

1) Narita, H., Noguchi, T., Maruyama, J., Ueda, Y., Hashimoto, K., Watanabe, Y., Hida, K.: Bull. Japan Soc. Sci. Fish 47, 935 941 (1981).

2) Maruyama, J., Noguchi, T., Jeon, J. K., Yamazaki, K., Hashimoto, K.: J. Food Hyg. Soc. Japan 24, 465 468 (1983).

3) Narita, H., Watanabe, K., Nara, M., Noguchi, T., Hashimoto, K.: Bull. Japan Soc. Fish in press.

4) Noguchi, T., Sakai, T., Maruyama, J., Jeon, J. K., Kesamaru, K., Hashimoto, K.: ibid. 51, $677 \sim 679$ (1985).

5) Noguchi, T., Jeon, J. K., Maruyama, J., Sato, Y., Saisho, T., Hashimoto, K.: ibid. in press.

6) Environmental Health Bureau, Ministry of Health and Welfare (ed.): "Food Hygiene Examination Manual" Vol. 2, Japan Food Hygiene Association, Tokyo, p. 232 240 (1978).

7) Hashimoto, Y.: "Marine Toxins and Other Bioactive Marine Metabolites" Japan Scientific Societies Press, Tokyo, p. 369 (1979).

8) Noguchi, T., Narita, H., Maruyama, J., Hashimoto, K.,: Bull. Japan Soc. Sci. Fish 48, 1173 1177 (1982).

9) Narita, H., Nara, M., Baba, K., Ohgami, H., Ai, T. K., Noguchi, T., Hashimoto, K.: J. Food Hyg. Soc. Japan 25, 251 255 (1984).

10) Maruyama, J., Noguchi, T., Narita, H., Jeon, J. K., Otsuka, M., Hashimoto, K.: Agric. Biol. Chem. in press. 